\title{
DISCURSO PROFERIDO PELO PROF. SAMUEL B. PESSÔA AO PARANINFAR OS DOUTORANDOS DE 1940
}

Quando, meus jovens e caros amigos, me escolhestes pelos votos, de vossa simpatia para paraninfar o ato solene que marca o fim de vossa despreocupada vida estudantina e o inicio de vossa vida médica, confesso-vos que, se me encantou, também não deixou de me causár. surpresa o ter sido eu, o mais obscuro dos vossos prófessores, o eleito para répresenta-los nêste comovido e já saudoso abraço dẹ despedidạ.

Considero a vossa escolha sincero ato de amizade, alta homehagem e gratíssimo prêmio a quem, quasi na mesma época, vê passar o decimo ano de magistério nesta escola. Assim si esta solenidade festiva é muito vossa, também o é um póuco minha, e o apadrinhar-vos nêste ano constitue para mim justa alegria e grande recompensa. Não. posso deixar que agradáveis recordações me elevem a alma, ao relembirar a minha investidura, ha um decênio, recebido no seio da Congregaçã்o pelo Professor RUBIÃO MEIRA, o Magnifico Reitor de nossa Universidade. Nossa Escola era então independente e sua fusão no organismo Universitário veio coroar o edificio do ensinó superior de-nossa terra. Aliás as Universidades brasileiras constituiram-se de modo bem diferente das Europeias. Nestas eram os homens ávidos de conhecimentos que se grupavàm e formavam uma Sociedade, cujo objeto era o áprendizado de todas as cousas cognosciveis, e daí tomarem o nome de "Universitas Studi Generaliss". Assim começou a existir no século XII a primeira Universidade, a 'de Paris. O reitorado apareceu devido ao rápido crescimento, fazendo-se necessária uma organização. Os professores e os escolares das. diversas disciplinas se reuniam para a eleição de um juiz e um governạdor supremo, o reitor, que era, naqueles tempos, o único representante da Universidade. Gozava de um poder tão real, que podia desafiar os prebostes de fóra e impor castigos corporais aos membros indisciplinados da Universidade. (Creio que muitos diretores de Faculdades lamentam ter passado tão aureo tempo!).

Entre nós, o processo de formação das Universidades foi justamente o contrário daquele da Universidade de Paris. Nesta, com efeito, só após longo tempo de funcionamento da sociedade de estudos gèrais, alguns dös mestres se consagraram ao estudo da teologia, outros ao do direito ou da medicina, e chegaram a ser doutores, isto é, membros instruidos nêstes ramos técnicos do saber. Como os semelhantes se atraem, os doutores formaram escolas ou faculdades 
de teologia, de direito ou de medicina, que, como acabamos de ver, nasceram de un processo natural de diferenciação.

No Brasil, diversamente, a organização social mais adiantada do que a educação intelectual, desde cedo precisou de técnicos, médicos, dentistas e advogados, para as necessidades mais comezinhas da vida; a filosofia, as ciências e as artes constituiram "importação pouco dispendiosa com que nos vamos servindo até hoje". Assim formaram-se as Universidades entre nós, como aglomerado de escolas técnicas e ainda pouco existe do verdadeiro espírito e da comunidade dos ideais Universitários. Talvez a organização da Faculdade de Filosofia, Ciências e Letras, como núcleo fundamental dos altos estudos destinados a fazer prosperar a investigação científica, exalte dentre poucos anos o verdadeiro espírito Universitário. Que o governo e a sociedade paulista saibam amparar e desenvolver econộmica e moralmente aquela escola, destinada no futuro a se constituir em "alma mater" da nos̄sa Universidade, donde deverão saír as elites dos nossos pesquisadores e os mestres das ciências desinteressadas de nossa terra. Vemos, de outro lado, com interesse e gratidão, os esforços desenvolvidos pelo atual Mağnifico Reitor para conseguir maior coordenação e mais estreita cooperação nos trabalhos dos vários Institutos Universitários, que nossa formação e talvęz nossa mentalidade muito individualista ainda não permitiram modificar. Devemos lembrar que o desenvolvimento científico de uma Universidade resulta sempre da mais estreita colaboração e cooperação entre as várias instituições que a compõem. $\mathrm{O}$ mesmo se pode notar quanto ao progresso da ciência em geral, que só se processa mediante a troca constante de idéias entre laboratórios de paizes, às vezes, muito distantes. Assim diz Fosdick "Si devido à exaustão e "os caos de guerra as Universidades e laboratórios da Europa fossem forçados a suspender suas atividades fundamentais durante somente meia decada, a consequência para a vida intelectual da America seria imediata e desastrosa". E a furia guerreira tem desintegrado quasi completamente a vida Universitária europeia. Não mais existem as Universidades de Varsovia e Cracovia, cujos membros estão mortos ou em campos de concentração; desapareceram as Universidades de Strasbourg, de Praga, fóra outras da Inglaterra e Alemañha, parcial ou totalmente destruidas pelos bombardeios. Os 20.000 estudantes da Universidade de Paris, já antes da entrada dos alemães naquela Capital, estavam reduzidos a 3.000 . Hoje, quantos serã.o? Temos assim cada vez mais de contar conôsco mesmos desenvolvendo não somente as escolas profissionais, mas também as que cultivam as ciências puras - fomentando os trabalhos de pesquisa para realizar o ideal Universitário - ensino das profissóes liberais, desenvolvimento da investigação científica e o preparo dos fufuros investigadores. Acima de tudo, porém, que do profissional, intelectual ou cientista, façam-se cidadãos à altura da situação de nossa Patria, dispostos e capazes de se devotarem ao serviço da nossa gente e da nossa terra. 
Recebeis, agora, meus jovens "colégas, o prêmio de vosso amôr 'ao estudo e devotamento ao trabalho; permiti-me, porém, recordar-vos. que, si êste diploma vos dá o direito de subir os degraus de uma longa esćadaria que vos deve levar muito alto, não vos deveis entretanto esquecer que degraus foram feitos para nêles nos determos somente o tempo necessário para atingirmos um outro mais acima.

$E$ assim, após gozardes a justa alegria de hoje, não passe ela de forte estimulo para vos ajudar a vencer as lutas de amanhã.

Aqui me detenho nos conselhos tão ao sabor de palavras como. estas, pois não quero que êste discurso se assemelhe a um sermắo. Lembrado estou de certo pregador, que, no auge do entusiasmo, bradou aos seus paroquianos: " $\mathrm{E}$ agora, o que deverei ainda dizervos ?"' E para surpreza dos ouvintes, ouviu-se o menino do côro, que já achava longa a arenga, responder: "Agora o Sr. pode dizer amem"!

Não, não vos quero fazer nenhưm sermão, porém, ao tentar: transmitir-vos a mensagem que aqui hoje me traz, sinto como oi poeta que

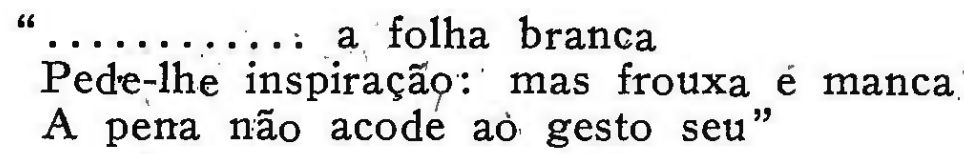

Si entretanto, fosse praxe o dar-se titulo a discursos de paraninfo, desejaria que êste se denominasse - "sôbre a necessidade de médicos rurais para o Brasil" ou então "sôbre a necessidade urgente de assistência médica e higiênica às populações rurais brasileiras". $\mathrm{E}$, antes de tudo, assistência aos nossos sertanejos, aos pioneiros das zonas novas, aos penetradores das matas e desbravadores da Natureza, daquela natureza brasileira bela e bravia, dadivosa e má, tão bem: retratada nos versos de Bilac:

\footnotetext{
"O' Natureza!' O' Mãe piedosa e pura!

$O^{\prime}$, cruel implacavel assassina!

Mão, que o veneno e o balsamo propina

$\mathrm{E}$ aos sorrisos as lagrimas mistura".
}

'Quero, porém, deixar bem claro que, thâo envolvem minhas palavras nenhuma critica a particulares ou ao governo, o qual nêstes. últimos tempos se orienta segundo uma politica sã de amparo ao nativo - constituem porém apreciações concretas de alguem que ama. seu país acima de tudo, e que tem sido sempre guiado pelo ideal deuma melhor e maior distribuição de saúde à nossa gente rural. Com. efeito, penso que nosso país, novo compo é, "atravessa fase de orgazação material, não tendo tido ainda-tempo de estratificar com rigor a mentalidade necessária a uma mais perfeita organização social". Porém todos nós que cultivamos a medicina e professamos das. "cátedras: oficiais, nos sentimos na "obrigação de encr rar com lealdadeos problemas de maior urgência para o desenvc vimento de nossa terra. 
Estou certo tambén que comungais comigo nêste sentido e poderemos juntos, nesta derradeira troca de impressões, encarar o maior problema médico do Brasil, pois sôbre os hombros da mocidade de hoje repousa a esperança da redenção do grande pecado da geração passada - o abandono de nossas populações rurais.

Não precisamos ir a 1916 quando Miguel Pereira, em seu estilo impar e ático, ao saudar a Aloisio de Castro disse sua celebre frase: "O Brasil é um imenso hospital". Porque ainda hoje não se compreende que no Brasil o brasileiro seja o que é. "O trabalhador na lavoura é explorado deshumanamente pelo patrão; o que ganha. não dá para a familia comer. Está sempre devendo na venda, emibriagando-se aos domingos para afogar as maguas. A ignorância do nosso caboclo é tão grande quanto a sua inteligência natural.' Ele contrae o amarelão e o impaludismo apenas pórque ninguem nasce sabendo, nem é possivel advinhar o que está nos livros da ciência”. (1) Toda razão assiste pois ao eminente mestre Prof. Aloisio de Castro, quando, em uma das suas mais brilhantes conferências realizada na Academia Nacional de Medicina, pede para o exercício profissional "um pouco menos de técnica e um pouco mais de coração"; o que o apostọlo brasileiro da higiene da criança, Oscàr Clark, comenta: "Sim, é de coraçã̃o que precisamos para melhorar a situação miserável em que se encontram a criança e o sertanejo em nosso país".

Meus jovens colegas:- Muito já se escreveu sôbre as misérias do Brasil - país imenso, porém pobre e despovoado. "Pobre porque sua principal fontè de riqueza é o sólo. Pode-se avaliar em mais de 15 milhões os que vivem da cultura do sólo na nossa patria. E são êles homens na sua maioria analfabetos e altamente anếmicos. Comó disse Oscar Clark, "a opilação, a fome crônica e a malária roubam-lhe até a última gota de sangue". Este mesmo higienista escrevéu: O Brasil é despovoado porque a criança vive no mais completo abandọ̣o entre nós. "A natalidade, entre nós é farța, mas o abandono em que jaz a criança e a ignorância das mães ceifam tantas vidas em flor, que quasi não vale a pena ter filhos no Brasil". Assim a mortalidade infantil em alguns municipios de $S$. Paulo chega a alcançar cifras pavorosas de 30\%. Segundo Teixeira Mendes Sobrinho, em Pindorama, temos o número absurdo de 511 óbitos de crianças até 2 anos de idade, sôbre um total de 776 falecimentos nos últimos 6 anos. isto é. a taxa incrivel de $65,8 \%$.

Qualquer criador de gado mudaria imediatamente de negocio caso a mortalidade nos seus rebanhos alcançasse $30 \%$ dos nascidos. Entretanto vemos que entre nós é justamente o fazendeiro, em geral o responsável, em larga extensão, pelo gra•ı de maior ou menor adian-

(1) Apud F. de Lemos. 
tamento sanitário, do éstado de higiene de suas propriedades e da saúde de seus colonos. Mesmo quando ao par das mais modernas conquistas da ciência só se mostra cạpaz de agir énergica e ciéntíficamente, quando se trata de proteger suas criações de porcos ou de gado, combater qualquer praga que por acaso apareça em seus algodoais, cafezais ou canaviais; ignora 'ou mostra-se refratário à aplicação dọs meios mais simples e econômicos para salvaguardar seus colonos e suas familias contra as moléstias parasitárias ou bacterianas mais perigosas. Tal fato não indica unicamente egoismo, ainda que - mostre em grande parte, antes porém, revela uma mentalidade.

-O fazendeiro educou e formou sua mentalidade na defeśa dos produtos de sua fazenda, e no deixar ao acaso a saúde e a vida de seus operários agricolas, e às vezes, até mesmo dos membros de sua própria familia. "Aliậs foi sempre assim. Dá-se maior valor econômico aos animais do que ao homem. Não escreveu Arthur Myers a respèito do problema da tuberculose que: "A familia do gado está ensinando a familia humaná como se libertar das garras da túberculose?". Vemos também que foi a Sociedade Protetora dos Animais que deu logar à formação da Sociedade Protetora da Cŕiança, nos Estados Unidos, conforme se depreende da leitura do livro tão interessante de Payne "The Child in Human Progress". "Mary Ellen era muitissimo maltratada pelos seus pais adotivos e nada se podia fazer a seu favor. Lembrou-se então uma vizinha de trazer o caso à Assembléia da Sociedade Prótetora dos Animais a qual, após longa discussão, deliberou que, sendo "a criança um animal". (the child being an animal), estava naturalmente sob a proteção da Sociedade. E, assim, cessaram as crueldades impostas a Mary Ellen e, aos 27 de Abril de 1875 era instalada a primeira Sociedade Protetora da 'Criança, na America do. Norte, (2)".

Sonhamos pelo dia que ao lado das Sociedades dos Caracus e Zebús, também se fundem as destinadas a zelar pela saúde dós nossos caboclos e operários agricolas.

Temos no Estado de S. Paulo, aquem do rio Paraná, uma vasta zona que compreende mais de $300 \mathrm{~km}$. de terras, que podemos atualmente considerar zona de desbravamento ou, como denominam hoje os americanos do Norte, zona pioneira. Monbeig, o geografo de nossa Universidade, quie a estudou pormenorisadamente, diz o seguinte: "A população da zona pioneira é uma imagem da pupuiaçảo do Brasil e, por suas variedades e pelos problemas que apresenta, imediatamente faz melhor compreender as questôes nacionais".

Estandó como estou de acôrdo com êste autor, analisemos a questão médica nacional tomando como espelho a análise do estado

(2) Apúd O. Clark. 
sanitário de uma localidade escolhida, ao acaso, na nossa zona pioneira, imagem da população brasileira. Seja por exemplo a Vila X na Alta Paulista, fundada pelo sistema do "patrimonio" há cêrca de 4 anos e alcançando hoje, com seus sitios e chacaras vizinhas, população que se pode calcular entre 1.400 a 1.500 habitantes. Em primeiro logar explicaremos o que significa o sistema "patrimonio", método que vem dando origem à maioria das cidades paulistas.' Um proprietário sente necessidade de vender grandes extensões de terras valorizadas pela penetração da estrada de ferro ou de rodagem, ou ainda para ter nas proximidades de sua lavoura, já constituida, uma aglomeração onde possa obter colonos em épocas certas do ano, para determinados serviços agricolas, como colheita ou plantio de algodão. Resolve então vender parte das terras em lotes que serão os "sitios", e outra parte reserva para o loteamento urbano - esta traz o nome de patrimonio. $O$ fundador simplesmente derruba as matas e traça as ruas em xadres. Organiza belissima planta do patrimonio onde se podem ver projetadas avenidas, igrejas, escolas etc., o que servirá de propaganda para a venda. $\mathrm{Na}$ realidade não constrói nem rede: de água ou esgotos e não se preocupa de saber si o local, por suas. condições topográficas, será posteriormente assolàdo pela malária. Abre apenas uma via de acesso.

Quanto ao Patrimonio de X que tomamos como exemplo; assim foi fundado e centenas de caboclos, paulistas, mineiros, nordestinos etc. aí se localizaram, nos sitios e na vila, atraídos pela propaganda e pela modicidade das prestações iniciais para a aquisição do seut lote. Estrangeiros poucos, alguns japonezes e raros italianos; são mais espertos e organizam-se de maneira melhor.

Qual a situação sanitária de Vila X? Ei-la na dura realidade dos números - $100 \%$ de seus habitantes são mal nutridos e opilados; $70 \%$ são afetados pela malária, sendo que $40 \%$ dêstes sofrem de malária maligna; $40 \%$ apresentam-se com leishmaniose, sendo que em $60 \%$ dêstes a moléstia invadiu as mucosas e em $10 \%$ as formas são mutilantes; $15 \%$ apresentam úlcera tropical fagéndênida e $10 \%$ estados ulcerosos da pele de várias outras etiologias; $100 \%$ são afetados pela sarna, que se complica, em numerosos casos, com: éctima, impetigo, etc.. Graças a Deus aquela zona ainda não foi invadida pela moléstia de Chagas e pelo penfigo; são estas doenças. das zonas mais velhas e assim, à medida que a leishmaniose após ter feito sua devastação através de mortes e mutilações se retira, começa a região a ser invadida pela tripanosomose e pelo penfigo. Finalmente, para que não se diga que alguma cousa foi poupada, ainda temos o tracoma, cegando e inutilizando numerosos dêstes pobres miseráveis.

Certos quadros de miséria, hão de me ficar na retina pelo resto de meus dias; são comuns para quem costuma perlustrar nossas zonas sertanejas e provam não haver exagêro no que vos conto. Só sinta 
não possuir leveza de pená e dons literários para descreve-los com as cores precisas com que os vi.

A escola: Visitava uma escola rural, modesta e pobre, como são todas aquelas das zonas sertanejas. Crianças sentadas no chão. batido, com seus caderninhos e livros ém cima de caixotes de querozene, pois bancos, carteiras, lousas ou qualquer outro material escolar, ainda não lhes haviam sido fornecido. Aliás dois anos após a situação permanecià a mesma. A porta aberta deixava entrar uma restea de sol, pois, na frescura matutina, as crianças pouco agasalhadas e mal nutridas sentian frio. Algumas mal podiam abrir os olhos, lesados pelo tracoma; outras, de um amarelo pálido e mucosas exangues, mostravam ao simples exame, "desnutrição, anemia e opilação. Obsérvẹi as atacadas pela laishmaniose, algumas com úlceras. na face a desfigurarem aquieles rostinhos bonitos e já sofredores. Temos aqui 32 crianças, disse-me a professora ; oito não vieram, pois. estão de cama com maleita - Duas outras tinham vindo mesmo tom febre. Com efeito, uma delas bastante pálida alí mesmo começou a ter vomitos biliosos! E a professora ao se despedir: - São todas doentinhas, e é tão dificil ensinar crianças doentes. Eu mesma depois que me mudei para aqui já tive diversos acessos de malária.

A familia: Úm pouco fora da Vila $Z$ e um pouco para dentroda picada que se dirige para as margens do rio Feio, avistei a casinha de pau a pique, esburacada e meio destelhada, que até então me passara despercebida. Aproximei-me e logo na porta avistei trềs crianças sujas, barrigudas, feridentas e tremendo de febre. Veio a mãe, moça-velha, estragada e sem dentes, palpebras vermelhas e sem pestanas, contrastando com os ol hos de córneas esbranquiçadas. por cicatrizes de tracoma antigo. Informou-me possuir, além daqueles três filhos, ùm outro maiorzinho na roça com o pai; já the tinham, mơrido quatro. Devido à propaganda tinham comprado aquelas terras. Alguns meses após tiveram úlceras, e ficaram sem tratamento. As noites, passavam-nas em claro, pois como as feridas. doiam muito com o frio, permaneciam junto do fogo, até acalmar a. dôr, e assim a noite toda até serem vencidos pelo cansaço. Quizeram mudar; a roça, porém, já estava plantada e aconselhatam-nos. esperar a colheita. Veio então a maleita, todos tiveran febres, dois morreram. Uma noite, tal foi o desespero que dela se apossou, que mal enxergando, misturou leite com creolina e deu para todos beberem. Morreu-1he mais um fịlho, o mais novo; e êstes três, terminou a martir, apontando aqueles rebotalhos , de infância, estão àinda muito doentes...

A Igreja: $\mathrm{Na}$ Vila $\mathrm{Y}$ encontrei-me no domingo com a padre alemão que á viera dizer missa, casar e batizar, como fazia regularmente ha mais de um ano cada 2 meses. Contou-me sua primeira missa na localidade. Ao entrar na igreja de madeira, recem-construida, sentiu tão mau cheiro, que o atribuiu a algum animal morto 
nas proximidades. Só depois percebeu seren as numerosas úlceras de seus paroquianos que exalavam aquele cheiro insuportável!

入̃ão desejó proseguir com semelhantes recordaçốes, pois não quero que um véo de tristeza empane o brilho deste festival. Porém é necessário que se não ignore o que se passa a alguns quilometros de nossa bela Capital, para que avalieis a responsabilidade que vai pesar sôbre os vossos hombros e quanto podeis contribuir para solucionar tão angustiosos problemas.

Do contrário ireis corroborar com um dos nossos mais brilhantes higienistas que disse em livro de grande repercussẩo entre nós e no estrangeiro: "há muita propaganda e muito septicismo, confunde-se verdade com proselitismo, e não é ciência é reclame. Umas verminoses, e logo se fala da raça carcomida, podre, inválida, desenganada... Pretexto médico para mensagens e discursos de salvação pública..." Mas, o que é interessante, é que êste mesmo autor, nêste mesmo livro se contradiz, pois vinte paginas adiante já nos desmerece já nos avalia a menos do que a outros povos e escreve: "Nós estamos em dieta... Por isso não' fazemos nada, ou pouco produzimos... Inquietos agitados... Aumenta-nos oș calculos estatísticos, a população... A produção não é proporcional. $O$ "standard" de vida não corresponde. Java e Cuba, modestas nações, produzem muito mais com menos gente. Sub-gente, sub-nação"!

$\mathrm{E}^{\prime}$ claro que nada poderemos concertar escrevendo ou deixando. de escrever livros... Fazendo polemica si os nossos caboclos são fortes ou fracos, nossas matas aléas do paraizo ou ante-câmaras do inferno. Os números aí estão; as estatísticas não mentem. Não é pretexto médico para campanhas de saneamento, pois não escreveu Monteiro Lobato, que não é formado em medicina, que "as nossas cidades se vêm forçadas a importar sangue de fóra, se querem escapar ao marasmo de uma senectude extemporânea. No interior do Brasil as cidades que se não retemperam ao modo de S. Paulo; caem na mais desalentadora caquexia. Os homens minguam de corpo, as mulheres são um restolho raquitico incapaz de bem desempenhar siquer a missão reprodutora".

Eis também o que escreve um engenheiro que bem conhece nossas zonas rurais: (3) "A falta de saneamento rural, as pessimas condições de higiene em geral e principalmente as de habitação, a deficiência de alimentação e de assistência médicà, aliadas a mais completa ignorância fazem do nosso trabalhador rural um enfermiço crônico". "S. Paplo, embora com tendência para um industrialismo intenso, foi sempre um Estado agrario $e^{\prime}$ deve o que tem ao campo. Entretanto, inconcebivel é o esquecimento para o qual tem sido relegado o nosso homem rural e iniqua a preferência que até o próprio Estado, em sua legislação, tem dado aos centros urbanos".

(3) Apud. T. Mendes Sobrinho. 
Observemos agora, um pouco, o colono estrangeiro; seja êle italiano, alemão, polaco ou japonez, que procura nossa patria e se localiza nos sertóes à cata de abundância e riqueza que thes negou a mãe Patría. Não são desprotegidos, pobres párias como o nacional. Vede por exemplo o japonez. Formam grandes companhias com sólidos capitais destinados a proteção do homem e do trabalho japoniez. Transcrevo um pequeno trecho de Monbeig (1940), que, por não ser brasiléiro, não pode ser taxado de jacobinista. Diz êste autôr ao falar da fazenda Bastos, colonizada por japonezes: "a cidade de Bastos, com o sub-prefeito naturalizado brasileiro, mas de origem japoneza, todos os hotéis japonezes, o mercado bi-hebdomadário sistematicamente organizado para venda de legumes colhidos nas hortas dos arrabaldes, as belas escolas de onde saem crianças que não compreendem uma palavra de português, o hospital com médicos e enfermeiros japonezes, etc.".

$\mathrm{E}$ os proprietários dos patrimonios nacionais?

Um dêles nós negou total e absoluta licença para instalarmos um posto de tratamento de Ưlcera de Baurú em sua propriedadé, onde existem $20 \%$ de leishmanióticos. $O$ pretexto para a recusa foi que um dispensário alí instalado tratia má fana para o patrimonio. Outro, riquissimo capitalista, convocou-nos para rogar-nos fechassemos o nosso posto instalado em seu patrimonio, pois o acúmulo de doentes em certas horas do dia trazia tão má impressão, que as vendas dos lotes estavam báixando consideravelmente.

E' como a primeira linha de combate na guerra, disseram-me certa vez - são os da vanguarda, os que mais morrem e mais sofrem; depois da derrubada dàs matas, desaperecem as úlceras; diminue a malária, a região se transforma e a terra fica produtiva e bốa. Eis a teoria do nacional.

Os estrangeiros porém, quando mandam sua gente para a vanguarda do sertão, arman-nos convenientemente - hospitais e escolas, água e esgotos, remédio, médico e enfermeiras ao primeiro chamado.

Dou como exemplo o núcleo de Novo-Oriente, hoje Pereira Barreto, colonizado pelos japonezes e que chegou a apresentar em 1934 um índice de $24 \%$ de impaludismo; o serviço de combate à malária por mim mesmo orientado durante 4 anos, e custeado pelos japonezes, fèz baixar êste índice a $0,5 \%$ o que, praticamente, fez desaparecer o perigo para a colonização, n'uma população de quasi 10.000 habitantes, dos quais mais de 9.000 são japonezes vivendo naquela zona potencialmente malarigena.

Si é pois dificil a organização de uma vida rural sadia e higiê nica, não é entretanto tarefa impossivel. Está farto o éstrangeiro de nos ensinar isso na nossa própria terra! E' necessário pois que se mưdem os métodos, se aperfeiçoem os estudo,s se dediquem os homens. 
Analisemos por exemplo o problema das verminoses que vem sendo combatidas por todos nossos sanitaristas, ha dezenas de anos no nosso Estado. Já tive ocasião de mostrar com números insofismáveis que, a-pesar dos vários anos que se escoaram de combate à Ancilostomose, continua a endemía helmíntica a prevalecer nas populações rurais, na mesma incidência e intensidade de ha 15 ou 20 anos atraz. Em grande parte a falha que se nota para conseguirmos maior progresso da higiene nas nossas zonas rurais, é a consequência de querer-se confiar exclusivamente ao Posto de Higiene ou Centro de Saúde a luta contra as moléstias predominantes nestas zonas.

A sociedade não se organiza, não se congrega e nem ha o auxílio econômico de quem pode dar, para que se constituam fundações auxiliares destinadas a preencher as lacunas inevitáveis dos serviços oficiais. Nova mentalidade deve presidir ao critério das doaçø̄es dos, nossos capitalistas, lembrando-se nêles das palavras de $\mathrm{S}$. Thomaz de Aquino, que disse ser o corpo também obra de Deus.

De outro lado, devemos nos capacitar que o problema da melhoria da higiene. nas zonas rurais constitue uma fase do problemra geral da educação. Quando se fala de educação geral, somente se pensa nas escolas primárias, parecendo futil tentar a educação sanitária dos adultos. Assim estamos todos de acôrdo que, às crianças, devem ser ensinadas nas escolas hábitos de limpeza e o perigo que. representa a poluição do sólo. Compreende-se, do mesmo modo, que tal ensinamento não terá nenhum valor, desde que seja feito em escolas desprovidas de instalações higiênicas ou que as possuam de peior qualidade. $E$ isto é o que se verifica entre nós frequentemente, pois justamente nas zonas rurais e mesmo nas sub-urbanas, constituem certas escolas, principalmente as escolas isoladas, os exemplos mais perfeitos de escolas anti-higiênicas. E' o quadro mais bem acabado do que não deve ser feito em matéria de higiene escolar. Para não vos dar a impressão de que exageramos ao dizer isto, citemos de passagem que, em seis escolas isoladas por nós visitadas ha dois anos em Sto. Amaro, isto é, situadas no próprio município de S. Paulo, em $100 \%$ delas encontramos na terra dos recreios ovos de Ascaris e Trichuris; e em $50 \%$ além daqueles, larvas infestantes do Necator (4).

Ressalta claramente que o saneamento da escola com o ensino de hábitos sadíos aos escolares, depende inteiramente da educação sanitária dos adultos, e que sem a cooperação inteligente dêstes adultos, não poderá ser feita com vantagens e educação sanitária dos.
escolares.

Outro fator, que se deve levar em consideração é o que se refere aos fundadores de "patrimonios" e organizadores de "vilas" e "çôesonias" no nosso "hinterland". E' necessário que tais organizações estejam realmente sujeitas a estricta fiscalização dos poderes

(4) Apud S. Pessóa e H. Pascale. 
competenteś afim de que aos povoadores para elas arrebanhados se garanta um mínimo de condiçốes de habitabilidade; água pura e esgotos; farmacia e assistência médica, escolas e enfermeiras, defesa contra a malária e outras endemias locais.

As escolas rurais devem se transformar em escolas hospitais ou escolas ambulatórios, e as professoras em professoras-enfermeiras. Pode parecer-vos estranha esta minha afirmativa, porém ela claramente resulta do fato de serem excepcionais as crianças sadias que as frequentam. A maioria e, em certas zonas, a totalidade carece de assistência médica constante e enfermeira carinhosa... Inumeras vezes temos verificado a bôa vontade das professoras, as quais condoidas do estado de saúde das crianças, se oferecem para tratar, sob indiçaçã́o médica, das principais moléstias que assolam seus alunos. E' claro que seria de proveito imediato a' administração de um curso de enfermagem prático e intensivo a essas dedicadas moças, de modo a se constituirem elas as melhores auxiliares da saúde do Brasil. Como disse Oscar Clark, "deve-se pedir o concurso decisivo da mulher para essa campanha sagrada de educação sanitária e de redenção física da raça. Medicina Preventiva exige alma de missionário e só a mulher de modo geral a possue. Ha nesse trábalho de saúde, fúnção para todas as moças brasileiras". O ideal de se espalhar educadoras sanitárias eficientes por todas escolas rurais é dificil de ser atingido. O curso é longo e caro. Poucas as que anualmente podem faze-lo. E com estas se verifica a mesma tendência que se observa nas demais profissões : a permanência nos grandes centros. O mais facil, eficiente e barato é um curso de enfermagem de alguns meses, onde aprenderiam elas como ajudar eficientemente o médico na, assistência aos eścolares, quanto às principais endemías rurais.

E' necessário também que nas nossas escolas médicas se desenvolva a mentalidade preventiva dos estudantes. Como disse Sr. George Newmann " $\mathrm{O}$ Espịito de Medicina Preventiva deve impregnar todo o ensino médico" realizando as palavras do pai dà Medicina - Hipocrates - "Si é glorioso cuidar dos doentes para restabelecer-. Thes a saúde, não é menos cuidar dos șãos para evitar sejam doentes;" Modifique-se radicalmente o ensino médico, para servir a mais alta finalidade da medicina - evitar a morte precoce.

Estou mesmo com os que acham que os nossos médicos recemformádos deveriam passar alguns meses no sertão.afim de se porem ao par dás necessidades médicas e mesmo sociais de nossos sertanejos.

Vede, meus jovens colegas, os nossos irmãos do sertão: soḅ o clima brando e puro dos campos e das matas; em contacto com a terra bôa e bemfazeja, que produz os mais ricos alimentos - nas matas e florestas, nos campos e montanhàs - morrendo mal ao nascer, degenerando si alcançam a idadé adulta - assolados por moléstiąs erradámente denominadas tropicais, - de facil prevenção e mais facil cura ainda.

Nós, que tivemos a felicidade de receber o benefício da civilização e da cultura, que nos permitiu retemperar o corpo e alçar o 
intelecto, devemos nos dedicar até o sacrifício, no desejo constante de fazer dêste país terra verdadeiramente generosa, não somente para alguns, porém para todos os seus filhos.

Trabalhai pois, meus amigos, porém trabalhai por êste alto e nobre ideal - o melhoramento da saúde de nosso povo; é êle um grande e imperioso dever social ao qual vos não podeis eximir.

E' o que esperamos de todos vós - o trabalho, o penoso trabalho - fonte de mérito e base de toda dignidade humana; pois "só o trabalho dá a liberdade e cada trabalhador é uma força social" (Ingenieros).

Sede a mais eficiente, a mais poderosa e a maior das forças sociais, para a saúde e redenção do Brasil. 


\section{Liceu Pan-Americano (PROPRIEDADE DA ESCOLA PAULISTA DE MEDICINA)}

\section{EXTERNATO PARA AMBOS OS SEXOS}

Sob o regime de inspecção federal permanente pelo decr. 1.533 de 15 de março de 1937

$\star$

DIRETORES:

Drs. Álvaro de Lemos Torreś e Antốnio de Carvạlho Aguiar C U R S O S :

Pré-Primário (Jardim da Infấncia)

Primário (4 anos)

Admissão ào Ginásio (I ano)

Ginasial Fündamental (5 séries)

Complementar Pré-Médico (2 séries)

Complementar Pré-Politécnico (2 séries)

Complementar Pré-Jurídico (noturno) (2 séries)

Curso de Preparação às Escolas Militares. (Escola Militar, Escola Naval, Esc. Prep. de Cadetes etc.)

MAGNÍFICOS LABORATÓRIOS DE FÍSICA, QUÍMICA E HISTÓRIA NATURAL:

ENSINO PRATTICO INTENSIVO.

Ótimos resultados colhidos nos concursos de habilitação realizados na Fac. de Medicina, Escola Politécnica, Fac. de Direito e Escola Paulista de Medicina.

\section{$\star$ \\ LICEU PAN-AMERICANO}

R. Visc. de Ouro-Preto, 51 (Consolação)

Tel.: 4-1587

SÃO PAULO 


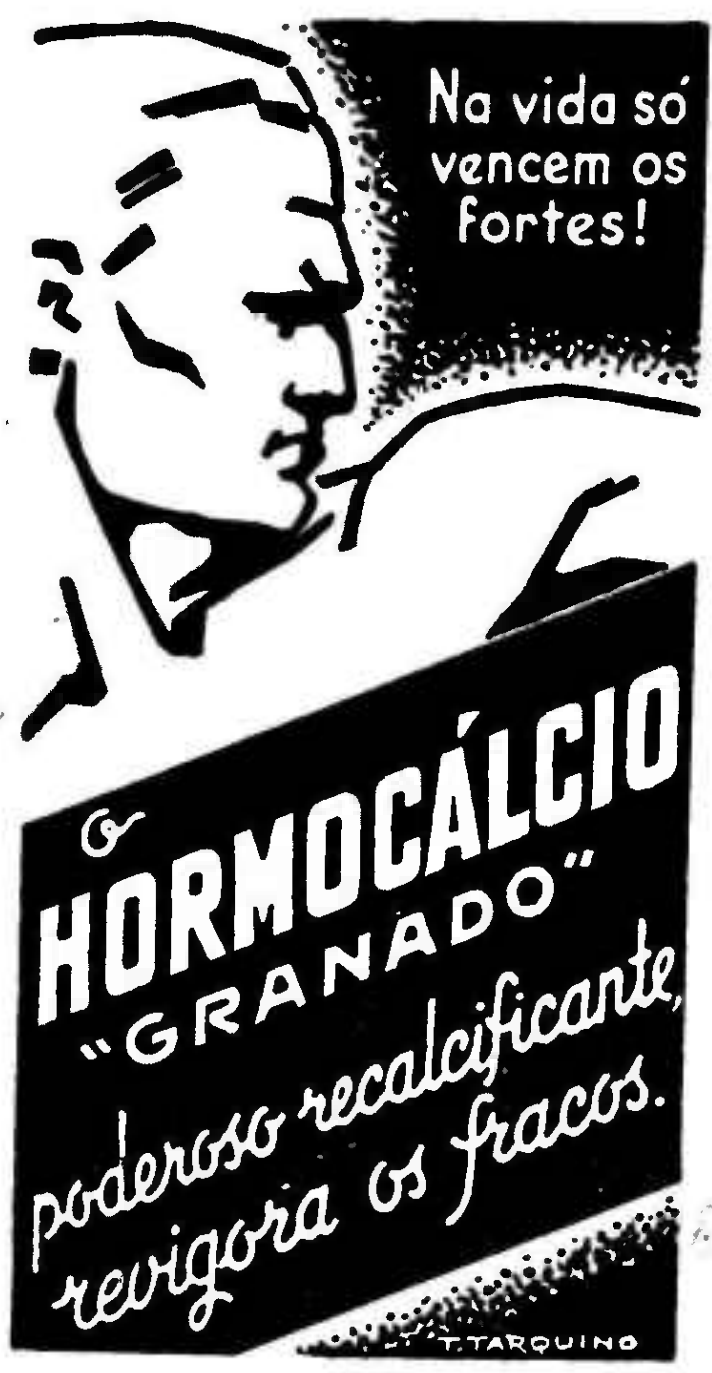

\section{ENDOSCOPIOS}

PARA TODOS

OSCASOS DE

DIAGNOSTICA

E CIRURGIA

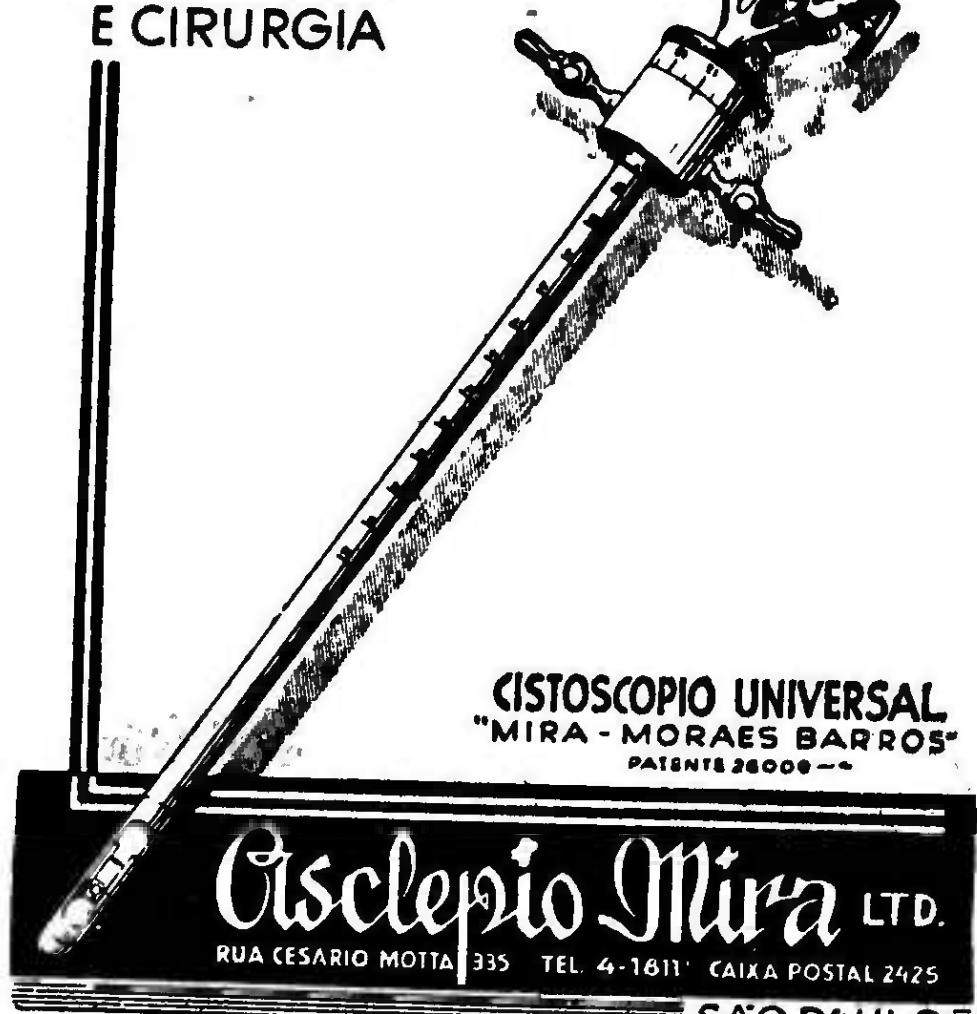

SA'O PAULOE

\section{Laboratorio "Imperial"}

RUA OLIMPIA, 124 - TEL. 5-7384

Fabricação Nacional de

CATGUT IMPERIAL - 000-00-1-2-3-4

Simples e cromado.

Tipo hospitalar (2,50 $\mathrm{mts}$.) e de urgencia (1 $\mathrm{mt}$.)

Agulhas atraumáticas - 00-0-1-2. Tipo especial para "enfuissement" do apêndice, com agulha
curva, n. $0,30 \mathrm{~cm}$ ts. de fio.

TENDōES DE KANGURÚ - fino médio, grosso, 30 ctms.

CRINA DE FLORÉNÇA - fina, média, grossa e extra-grossa.

Seda Branca Trançada - 000-00-0-1-2-3-4-5.

Tipo Hospitalar (2,50 mts.)

Tipo de urgência $(1,25 \mathrm{mts}$.)

Produtos adotados na maioria dos Hospitais do Brasil Amostras e literatura: DI GIULIO \& Cia.

Rua Felipe de Oliveira, $21-6 .^{\circ}$ andar - Telefone 2-8194 